PSI COLOGI A SOCI AL

\title{
o processo de revelação do abuso sexual intrafamiliar na percepção do grupo familiar
}

\section{The disclosure process of intrafamily sexual abuse in the family group's perception}

\section{El proceso de revelación del abuso sexual intrafamiliar en la percepción del grupo familiar}

\author{
Márcia Moraes Lima Coutinho* \\ Universidade de Fortaleza - UNIFOR, Fortaleza, Ceará, Brasil \\ Normanda Araujo de Morais** \\ Universidade de Fortaleza - UNIFOR, Fortaleza, Ceará, Brasil
}

\begin{abstract}
RESUMO
O presente artigo buscou descrever a percepção do grupo familiar sobre o processo de revelação de uma situação de abuso sexual intrafamiliar. Realizou-se um estudo de caso único de uma família, cuja filha foi vítima de abuso sexual dos 9 aos 14 anos, perpetrado pelo padrasto. A metodologia da Inserção Ecológica serviu de estratégia para coleta de dados, sendo que foram entrevistados individualmente sete pessoas: vítima, mãe e irmão mais velho da vítima, pai biológico, vizinha, liderança da igreja e a psicóloga que atendeu a vítima na época da revelação do abuso sexual. Além da entrevista, utilizaram-se outros instrumentos, como diário de campo e prontuário da vítima disponível no CREAS. Verificou-se que o processo de revelação foi favorecido pelo apoio de diferentes personagens e contextos, como o próprio grupo familiar (irmão mais velho, pai biológico), a rede de apoio informal (vizinha e liderança da igreja) e a rede de apoio Institucional (CRAS e CREAS). Dessa forma, reafirma-se a importância do fortalecimento das relações comunitárias nas famílias vítimas de violência sexual, da rede de apoio socioassistencial, bem como da perspectiva sistêmica sobre a família e o abuso sexual.
\end{abstract}

Palavras-chave: abuso sexual, rede de apoio, família.

\section{ABSTRACT}

This article aimed to describe the perception of the family group about the disclosure process of intrafamily sexual abuse situation. A single case study of a family was conducted, whose daughter was a victim of sexual abuse from 9 to 14 years old, perpetrated by her stepfather. The methodology of Ecological Insertion served as data collection strategy, being that seven people were interviewed individually: victim, victim's mother and older brother, biological father, neighbor, church leadership and the psychologist who attended the victim at the time of the sexual abuse revelation. In addition to the interview, other instruments were used, such as field journal and the victim's record available at CREAS. It was verified that the 
disclosure process was favored by the support of different characters and contexts, such as the family group (older brother, biological father), the informal support network (neighbor and church leadership) and the institutional support network (CRAS and CREAS). Thus, it reaffirms the importance of strengthening community relations of families victims of sexual violence, social support network, as well as the systemic perspective on the family and sexual abuse.

Keywords: sexual abuse, support network, family.

\section{RESUMEN}

El presente artículo procuro describir la percepción del grupo familiar sobre el proceso de revelación de la situación de abuso sexual intrafamiliar. Se realizó un estudio de caso único de una familia, cuya hija fue víctima de abuso sexual de los 9 a los 14 años, perpetrado por el padrastro. La metodología de la Inserción Ecológica sirvió de estrategia para colecta de datos, siendo que fueron entrevistados individualmente siete personas: víctima, madre y hermano mayor de la víctima, padre biológico, vecina, liderazgo de la iglesia y la psicóloga que atendió a la víctima em la época de la revelación del abuso sexual. Además de la entrevista, se utilizaron otros instrumentos, como diario del campo y prontuario de la víctima disponible en el CREAS. Se verificó que el proceso de revelación fue favorecido por el apoyo de diferentes personajes y contextos, como el propio grupo familiar (hermano mayor, padre biológico), la red de apoyo informal (vecina y liderazgo de la iglesia) y la red de apoyo institucional (CRAS y CREAS). De esta forma, se reafirma la importância del fortalecimiento de las relaciones comunitárias en las famílias víctimas de violencia sexual, de la red de apoyo socio asistencial, así como de la perspectiva sistémica sobre la familia y el abuso sexual.

Palabras-clave: abuso sexual, red de apoyo, familia.

\section{I ntrodução}

O Estatuto da Criança e do Adolescente- ECA (1990), artigo 5o, prevê que nenhuma criança ou adolescente poderá ser objeto de qualquer forma de violência, sob pena de punição na forma da lei, seja por ação ou omissão, aos seus direitos fundamentais. No entanto, é notória a maior visibilidade que a mídia, políticas públicas e produções acadêmicas têm dado aos casos de crianças e adolescentes que sofrem alguma forma de violência. Em todos esses espaços, por sua vez, tal fenômeno é descrito como um problema de saúde pública, em virtude das suas estatísticas de incidência e das consequências (físicas e psicossociais) que potencialmente podem gerar.

A violência sexual cometida contra crianças e adolescentes, conforme a Organização Mundial de Saúde - OMS ocorre pelo envolvimento de uma criança em atividade sexual sem que a mesma tenha compreensão total da situação ou para a qual não está preparada emocionalmente em virtude da sua idade ou estágio de desenvolvimento (World Health Organization [WHO] \& International 
Society for the Prevention of Child Abuse and Neglect [ISPCAN], 2006). Tal violência está implicada numa dinâmica de relação de poder do agressor sobre a vítima, cujo objetivo é a busca pelo prazer sexual do primeiro, seja pela estimulação da vítima ou pelo uso desta para a obtenção de prazer sexual (Cerqueira-Santos, Rezende, \& Correia, 2010; Silva, Gava, \& Dell'Aglio, 2013; Habigzang, Koller, Azevedo, \& Machado, 2005; Habigzang, Azevedo, Koller, \& Machado, 2006).

O abuso sexual inclui atividades sexuais onde não há contato físico (voyeurismo, assédio, exibicionismo); onde há contato físico sem penetração (toques, carícias, sexo oral); ou ainda quando existe contato com penetração (digital, genital ou anal) (Habigzang et al., 2006; Lugão et al., 2012). Alguns autores caracterizam o abuso sexual como uma progressão ascendente, no qual o agressor, aos poucos, por meio de carícias sutis vai progredindo nas agressões passando pela manipulação genital, podendo chegar ao intercurso sexual oral ou genital. Há evidências de violência nessas práticas eróticas e sexuais contra a criança ou ao adolescente, seja físico uso da força ou psicológica - pela coerção, indução, sedução e indução de sua vontade (Habigzang et al., 2005).

No entanto, entende-se que o impacto psicológico sofrido pelas vítimas pode ser de diversas naturezas e as alterações podem se apresentar em curto e/ou longo prazo a partir dos episódios abusivos (Silva, Gava, \& Dell'Aglio, 2013). As autoras chamam a atenção para outros fatores diferentes ligados à própria violência que podem alterar o impacto desta sobre a vítima, quais sejam: a duração do abuso, o grau de violência ou ameaça, a idade de início do abuso, o grau de segredo, a diferença de idade entre abusador e vítima, grau de relacionamento entre a criança e o abusador, presença de penetração genital, dentre outros.

Há, ainda, o relato de vítimas que não apresentam consequências negativas decorrente do episódio abusivo. Nesse caso, a ausência de sintomas é atribuída a diversos fatores intrínsecos (o tipo de relação com o agressor, características pessoais e estratégias utilizadas, por exemplo) e extrínsecos à vítima (recursos sociais, a punição que o perpetrador recebeu; dinâmica familiar, reação dos familiares frente à revelação do abuso, o apoio familiar e/ou profissional que recebeu antes e após a revelação), funcionando estes como mediadores do impacto da violência sobre a criança /adolescente (Habigzang et al., 2006).

Estudiosos sobre desenvolvimento humano como Bronfenbrenner (1979/1996, 2011), por exemplo, citam a família como um importante contexto de desenvolvimento, visto fazer parte do nicho ecológico de maior contato da criança. No entanto, tal contexto pode favorecer ou dificultar o desenvolvimento da criança, constituindo-se com um fator de risco ou de proteção ao desenvolvimento dos seus 
entes, a depender da qualidade das relações estabelecidas entre os membros e destes com o entorno (Morais, Lima, \& Fernandes, 2014). Nos estudos sobre abuso sexual, por sua vez, a família tende a ser descrita de forma muito restrita, ou seja, focalizando-se apenas a figura materna, uma vez que é ela geralmente a primeira pessoa a quem a vítima informa sobre o acontecido (Habigzang et al., 2005; Lima \& Alberto, 2010; Santos \& Dell'Aglio, 2010). No entanto, percebe-se uma tendência de que essa mãe seja descrita como conivente e culpada pelo abuso, como relatado no estudo de Penso, Costa, Almeida, e Ribeiro (2009); ou a ser vista de forma ambivalente, pois tende a alternar comportamentos como o de acreditar/não acreditar na vítima e denunciar/não denunciar 0 agressor (Santos \& Dell'Aglio, 2008).

De fato, ainda é dada pouca atenção à escuta do grupo familiar e a uma visão sistêmica-relacional que considere simultaneamente as múltiplas vozes existentes na família, seja a da vítima, a dos pais biológicos, padrastos, irmãos, avós ou outras pessoas descritas como fazendo parte da família. Assim sendo, esse artigo sublinha a importância de estudos que envolvam o grupo familiar e não apenas a visão de um ou outro componente da família (Böing, Crepaldi, \& Moré, 2008).

Ademais, outra contribuição se dá na esteira dos estudos que focalizem os processos saudáveis das famílias, para além das adversidades vivenciadas (Walsh, 2005). Nesse caso, o foco é sobre a descoberta e fomento de indicadores e processos relacionais que possam atuar diminuindo o impacto da violência sobre a criança e o sistema familiar como um todo; antes que na descrição de sintomatologias ou prejuízos ao desenvolvimento (Coutinho, 2015; Rosa \& Lira, 2012).

O processo de revelação do abuso sexual constitui-se como um elemento-chave para a compreensão dos desdobramentos que esta violência pode gerar na vida das vítimas e suas famílias. A credibilidade que uma vítima recebe quanto ao seu relato, bem como a existência de uma rede de apoio social e afetiva - interna ou externa à família - é central para um prognóstico mais positivo e protetivo para a vítima de violência sexual, uma vez que funciona como um importante mediador do impacto da violência sexual sobre a vítima (Habigzang et al., 2006; Rosa \& Lira, 2012; Santos \& Dell'Aglio, 2013).

A rede de apoio social e afetiva é definida como um conjunto de sistemas e de pessoas significativas que incluem os elos de relacionamentos recebidos e percebidos pelo indivíduo (Brito \& Koller, 1999). De acordo com tais autoras, pode ser avaliada em três dimensões: o número de elos da pessoa com o ambiente; a frequência de transações de apoio e reciprocidade; e, por fim, a avaliação que a pessoa faz sobre os apoios (percepção de intimidade 
e proximidade sobre os mesmos). Em vários estudos sobre crianças e/ou seus familiares, em situações de vulnerabilidade, tem-se investigado a rede de apoio social e afetiva como nas pesquisas de (Dias \& Leite, 2014; Nascimento \& Rosa, 2015; Siqueira \& Dell'Aglio, 2010, por exemplo).

Estudos mais recentes retratam diferentes aspectos que envolvem o processo da revelação do abuso sexual contra crianças e adolescentes, a saber: a caracterização da revelação do abuso sexual infantil (Baía, Velloso, Magalhães, \& Dell'Aglio, 2013); caracterização da notificação compulsória do abuso sexual infantil (Lima \& Deslandes, 2011); a trajetória da vítima da notificação ao processopenal (Dobke, Santos, \& Dell'Aglio, 2010); reações maternas diante da revelação (Lima \& Alberto, 2010; Mattos \& Lima, 2012; Santos \& Dell'Aglio, 2008; 2009); estratégias adotadas pelas mães diante da revelação (Inoue \& Ristum, 2010); processo da revelação na percepção de mães da vítima (Santos \& Dell'Aglio, 2013); fatores que inibiram a revelação do abuso sexual (Santos \& Dell'Aglio,2010); e medidas adotadas pela rede de apoio institucional na revelação do abuso sexual (Habigzang, Ramos, \& Koller, 2011); perspectiva de adolescentes sobre o apoio social recebido após o abuso sexual (Schönbucher, Maier, Mohler-Kuo, Schnyder \& Landolt, 2014).

Em conjunto, os estudos acima mencionados contribuem significativamente para uma maior compreensão do processo da revelação do abuso sexual contra crianças e adolescentes. No entanto, confirma-se a tendência desses estudos de privilegiar a visão de apenas um membro da família (ora a mãe, ora a vítima, predominantemente); negligenciando a perspectiva do grupo familiar e, portanto, a visão de que vários membros da família (pai, irmão/s, dentre outros) têm sobre a situação de violência sexual vivenciada e, consequentemente, sobre o processo de revelação do abuso. Tão negligenciado quanto esse aspecto são os estudos que descrevem as medidas de enfrentamento adotadas pelos diversos membros da família, em momentos de vulnerabilidade, como no processo da revelação do abuso sexual.

Portanto, visando agregar uma contribuição às lacunas acima mencionadas, esse artigo tem como objetivo descrever a percepção do grupo familiar sobre o processo de revelação de uma situação de abuso sexual intrafamiliar. Realizou-se um estudo de caso único de uma família, cuja filha foi vítima de abuso sexual dos 9 aos 14 anos, perpetrado pelo padrasto.

\section{Método}

O presente estudo utilizou-se da abordagem qualitativa, descritiva e exploratória, através do uso do delineamento de Estudo de Caso 
Único (Yin, 2010), uma variação de estudo de caso, cujo objetivo "é investigar um fenômeno contemporâneo em profundidade e em contexto de vida real" (p. 39).

\subsection{Participantes}

Participaram desse estudo quatro integrantes da família que vivenciou o abuso sexual intrafamiliar: a vítima, a mãe, irmão mais velho e pai biológico da vítima. Outras três participantes (vizinha, liderança da igreja e psicóloga do Centro de Referência Especializada de Assistência Social [CREAS] responsável pelo atendimento da vítima) também foram incluídas na pesquisa, uma vez que foram identificadas pela figura materna como sendo pessoas-chave no processo de revelação do abuso. O presente estudo, portanto, está em consonância com o estudo de Böing et al. (2008), segundo o qual o sistema familiar é compreendido de forma ampliada, incluindo também o ambiente sócio-comunitário. Os critérios de seleção da família participante são descritos na seção de Procedimentos.

\subsection{Instrumentos}

Entrevistas semi-estruturadas (participantes adultos)

As entrevistas foram do tipo semi-estruturadas com os participantes adultos (mãe, irmão mais velho, pai biológico, vizinha, liderança da igreja e psicóloga) e tinham como objetivo favorecer o desenvolvimento de narrativas de forma mais livre pelos participantes, como se pode verificar nos exemplos a seguir: "Conteme o que você lembra sobre o processo da revelação do abuso sexual?"; "Qual foi a sua participação?".

\section{Entrevistas estruturadas (vítima)}

A entrevista com a vítima aconteceu de forma mais estruturada, utilizando, inclusive, de recursos auxiliares a fim de facilitar o rapport e a expressão de sentimentos e relatos da experiência vivida. Em um primeiro momento, por exemplo, utilizou-se o Mapa dos Cinco Campos, baseado nos estudos de (Morais, Koller \& Raffaelli, 2012), é um instrumento lúdico, confeccionado em feltro e neste há desenhos de círculos concêntricos que representam a relação de proximidade com o participante. Há também figuras que representam crianças, adolescentes e adultos que podem ser fixadas (com velcro) dentro dos círculos, no mapa do participante. No círculo central (o menor) é posicionado o participante. Quanto mais próximo os representantes estiverem do participante maior será a relação de proximidade entre os mesmos. A finalidade é identificar a rede de apoio da vítima 
(quantidade e definição das pessoas que fazem parte da sua vida nos espaços da família, escola, igreja, Instituição, amigos), bem como os níveis de proximidade com estas mesmas pessoas.

Também se aplicou uma sequência de sentenças incompletas, visando identificar figuras de apoio, percepções sobre o presente e perspectivas sobre futuro ("A pessoa com quem conto quando estou num conflito é...; Quando preciso de ajuda eu...; Tenho planos de...).

Diário de Campo

Permitiu o registro de dados desde as primeiras impressões da pesquisadora sobre a sua inserção no CREAS, além de registros diversos sobre todo o período que durou a pesquisa, principalmente sobre a inserção na casa da família participante e na comunidade na qual a mesma reside, dados considerados imprescindíveis para a análise dos dados (Afonso, Silva, Pontes, \& Koller, 2015).

Prontuário da Vítima

Os dados do prontuário da vítima, existentes no CREAS, foram acessados e ajudaram a construir o histórico de atendimentos da vítima na Instituição (período em que a vítima foi atendida, eventos situacionais, interrupções, por exemplo).

\subsection{Procedimentos de coleta de dados}

A Inserção ecológica foi utilizada como proposta metodológica para a inserção da pesquisadora no CREAS e junto à família participante (Cecconello \& Koller, 2003). Em linhas gerais, a inserção está baseada na proposta de estudo do desenvolvimento humano no contexto, tal como proposto pela Abordagem Bioecológica do Desenvolvimemento Humano (ABDH), desenvolvida por Urie Bronfenbrenner. Operacionalmente, implica a inserção gradual e prolongada no contexto de pesquisa, visando ao estabelecimento de uma relação de confiança e maior proximidade com seu objeto de estudo, de acordo com a proposta de (Paludo \& Koller, 2005; Vasconcelos, Yunes \& Garcia, 2009). Nesse estudo, a inserção teve a duração de três meses e implicou em visitas sistemáticas ao CREAS e à residência da família participante, bem como contato telefônico com estes. Os registros das visitas ao campo de pesquisa e dos contatos telefônicos eram feitos no diário de campo da pesquisadora.

O estudo buscou uma família por meio do CREAS de um município da região metropolitana de Fortaleza, CE. A família foi indicada pelas técnicas (psicólogas e assistentes sociais) que trabalhavam naquele equipamento. A elas foi pedido que listassem famílias nas quais o agressor tivesse sido afastado da vítima; a vítima não estivesse mais 
submetida à situação de violência sexual; tivesse sido atendida pelo CREAS; e estudando/trabalhando na época da realização da pesquisa. As técnicas indicaram uma relação de sete famílias, sendo que destas conseguiu-se contato apenas com uma família. A mãe da família participante foi a única que atendeu ao telefonema e logo se prontificou a participar, tendo sido marcado uma visita à sua residência pela pesquisadora.

Tendo a mãe aceito o convite, solicitou-se à mesma que indicasse outras pessoas que pudessem participar do estudo, cujo envolvimento estivesse diretamente ligado ao processo de revelação do abuso sexual, bem como que estivessem ligadas ao enfrentamento da situação. A mãe indicou oito pessoas, sendo que apenas cinco aceitaram participar (pai biológico, filho mais velho, vizinha, liderança da Igreja e a psicóloga que atendeu a filha na época da revelação do abuso).

Após contato telefônico prévio, todos os participantes indicados pela mãe foram entrevistados individualmente e em locais de sua escolha. A ordem das entrevistas foi a que segue e entre parênteses consta 0 número de encontros com cada um/a: 1) vizinha (dois encontros); 2) mãe (dois encontros); 3) liderança da Igreja (um encontro); 4) filho mais velho (um encontro); 5) vítima (dois encontros); 6) pai biológico (um encontro); e 7) psicóloga (um encontro). No total, portanto, realizaram-se dez entrevistas, com duração média de 45 minutos cada. Todas as entrevistas tiveram o áudio gravado. 0 número de entrevistas com cada participante variou de acordo com a disponibilidade de tempo de cada um/a para participar da pesquisa.

\subsection{Procedimentos de análise de dados}

Utilizou-se a proposta de Análise de Conteúdo (Bardin, 1995) para análise dos dados. Tal estratégia de análise consiste nas seguintes etapas: a) pré-análise, que é composta pela leitura flutuante, ou seja, o pesquisador deixa-se impregnar pelo conteúdo, por meio de exaustivo contato com o material, para constituir o corpus e formular algumas hipóteses de trabalho; b) exploração do material, que consiste em separar as categorias ou eixos temáticos, a serem discutidos adiante; e c) análise e interpretação dos resultados, com base na literatura consultada a escuta do áudio das entrevistas a fim de iniciar uma pré-análise e construção dos eixos temáticos de análise, a partir dos quais os conteúdos das diversas entrevistas puderam ser agrupados. Os dados dos vários instrumentos foram triangulados a fim de compor uma visão integrada das informações coletadas. 


\subsection{Procedimentos éticos}

A pesquisa atendeu às recomendações bioéticas para pesquisas com seres humanos, conforme a Resolução 466/2012 do Conselho Nacional de Saúde (CNS) e recebeu aprovação do Comitê de Ética da Universidade de origem das autoras desse artigo (Parecer 1.013.765). Dessa forma, todos os participantes adultos assinaram o Termo de Consentimento Livre e Esclarecido (TCLE), enquanto que a participação da vítima - adolescente foi autorizada pela figura materna.

\section{Resultados e discussão}

\subsection{Descrição do caso}

A família é constituída por mãe (Maria, 43 anos, diarista), e quatro filhos: Márcio (26 anos), Joana (17 anos), Melissa (9 anos) e Marcela ( 7 anos). Todos os nomes aqui apresentados são fictícios para preservar a identidade da família.

Joana, foi abusada pelo padrasto (Lucio) desde os 9 anos, tendo revelado os abusos aos 14 anos. O contato com seu pai biológico geralmente se dava via facebook ou em momentos em que a filha encontrava-se em crise com a mãe, uma vez que mãe e pai biológico não tinha uma relação amigável. Já Marcio que tinha uma relação de proximidade com Joana, funcionava como uma espécie de link entre mãe e irmã em momentos de crise entre as duas. Joana, era uma adolescente que gostava de estar entre os pares, nunca deixou de estudar, gostava de escrever e fazer poemas (incentivados pelo pai biológico) e frequentava um grupo de jovens da Igreja. A mãe de Joana, Maria, foi morar com sua irmã mais velha, Celeste, aos 17 anos, após a sua primeira gravidez (fruto do primeiro relacionamento), e permaneceu até a chegada de Lucio na família. Os quatro filhos são frutos de três relacionamentos de Maria. Em todos os relacionamentos, sempre havia conflitos familiares envolvendo Maria, o companheiro e Celeste. Tais conflitos resultavam em afastamento dos referidos companheiros da mãe e a permanência da família na casa da tia. No entanto, com a chegada de Lucio (homem bem mais velho que Maria, separado, pai de dois filhos adultos, fruto do primeiro casamento) aconteceu de forma diferente, tendo em vista que Maria resolveu aceitar o convite do companheiro para sair da casa da irmã Celeste. Tal decisão resultou em mais um conflito familiar envolvendo Celeste, Maria e Lucio, já que Celeste não aceitava ficar longe dos sobrinhos: Joana e Márcio. O conflito resultou em rompimento entre as irmãs; permanência de Márcio na casa de 
Celeste; e saída da família para outro município, onde foram morar Maria, Lucio, Joana e suas irmãs mais novas.

Os abusos do padrasto de Joana começaram a acontecer logo após a mudança, quando Joana contava com 9 anos de idade. Aos 14 anos, Joana revelou os abusos sofridos. Primeiramente, relatou a violência para Cláudia (liderança de jovens na igreja e amiga de Maria), a mesma a encorajou a revelar para a mãe. Com a revelação dos abusos, Maria apresentou dificuldades em acreditar na filha, mesmo assim, colocou o agressor para fora de casa. De acordo com o prontuário da vítima, houve uma denúncia anônima sobre o caso, resultando em acolhimento e acompanhamento da vítima pelo CREAS. Na época da pesquisa, três anos após a revelação, Joana não se encontrava em atendimento pelo CREAS, nem frequentando o grupo de jovens da Igreja, no entanto, continuava estudando, terminando o ensino médio e preparando-se para o Exame Nacional do Ensino Médio (ENEM).

\subsection{Descrição do processo da revelação do abuso sexual}

O processo de revelação do abuso sexual intrafamiliar e seus desdobramentos tornam-se chave para compreender as condições que podem favorecer um ambiente mais ou menos protetivo/vulnerabilizador para a família. Nesses termos, torna-se necessário investigar o que estava acontecendo com a família antes da revelação dos abusos do padrasto e quais as circunstâncias que dificultaram e/ou facilitaram a mesma. Além disso, é igualmente importante saber quais mudanças foram deflagradas no sistema familiar que possa ajudar a entender qual (is) recurso(s) a família utilizou/buscou para enfrentar tal situação.

As dificuldades encontradas pela vítima para revelar o abuso referemse ao isolamento emocional presente no sistema familiar e ao medo que a vítima tinha sobre as consequências que a revelação poderia causar à família. No entanto, houve estressores adicionais que mobilizaram a vítima para revelar os abusos primeiramente para Cláudia (liderança da igreja) e posteriormente para a mãe: a morte da tia Celeste e as proibições do padrasto de Joana viver a relação com os pares.

Em relação à notificação dos abusos sofridos, houve vários fatores que dificultaram que Maria fizesse a notificação dos abusos sofridos por Joana, tais como: a visão idealizada de família, ameaças recebidas da filha do primeiro casamento do agressor, além da dependência emocional e financeira do agressor. No entanto, houve também fatores que facilitaram a notificação dos abusos, como os apoios advindos de várias pessoas que participaram no processo da revelação (liderança da igreja, vizinha, diretora da escola), bem como 
do próprio sistema familiar (pai biológico da vítima e irmão mais velho).

No tocante às consequências da revelação do abuso sexual para a família, sobressaem-se: a saída do agressor de casa e as dificuldades financeiras na família. Tais resultados estão de acordo com estudos que buscaram compreender o processo da revelação do abuso sexual intrafamiliar a partir de diferentes atores (Lima \& Alberto, 2010; Mattos \& Lima, 2012; Santos \& Dell'Aglio, 2009; 2010).

Assim, os pensamentos da vítima em momentos que antecederam a revelação trazem evidências sobre suas percepções e sentimentos sobre seu ambiente: "Foi tipo assim, poxa se eu quiser contar pra alguém vai ser pra ela [Tia Celeste], porque ela já desconfia. E depois ela faleceu. Aí eu pensei: “Cara, não tem mais ninguém!'” Suas declarações revelam um ambiente caracterizado pelo isolamento emocional, considerado um fator de risco para o abuso sexual intrafamiliar (Santos, Pelisoli, \& Dell' Aglio, 2012).

Há evidência de que, nessa época, Joana percebia apenas na pessoa da tia (Celeste) a possibilidade de apoio. A posterior morte da tia pode ter sido um estressor adicional para que Joana buscasse alguém de fora do núcleo familiar para revelar o abuso do padrasto, sendo primeiramente para Cláudia, a liderança de jovens da Igreja, e depois para a mãe. Em sua entrevista, Cláudia conta que foi a primeira pessoa escolhida por J oana para revelar sobre o abuso:

Aí ela veio conversar comigo né... Ela me perguntou o que era que eu poderia aconselhar a ela, se ela contava pra mãe ou se ela deixava acontecer até ela chegar a maior idade e sair de dentro de casa e não querer mais nem ver ele. Aí o pensamento dela era esse: desligar da família.

As motivações que Joana alegou para não contar sobre o abuso corroboram os estudos que apontam o medo da vítima sobre as consequências que a revelação pode causar para a família (Santos \& Dell'Aglio, 2010). Nas palavras de Cláudia: “Foi o que ela me falou: 'E eu não quero estragar a felicidade deles [dos familiares - mãe, padrasto e irmãs mais novas]'". Tais motivações também apontam para a complexidade do fenômeno do abuso sexual quando o mesmo é do tipo intrafamiliar, ou seja, quando o perpetrador é uma pessoa em quem a mãe confia e que é geralmente o provedor financeiro da casa (Santos \& Dell'Aglio, 2009). Ao mesmo tempo, demonstra o nível de lealdade da vítima para com o sistema familiar, estando a mesma envolvida na dinâmica do segredo, tão característica de famílias nas quais a violência sexual ocorre (Santos et al., 2012).

A declaração de Cláudia aponta para as circunstâncias que também podem ter motivado Joana a romper com o silêncio: 
Porque se chegava uma amiguinha e dizia: "Joana, vamos passar uma tarde lá em casa"... Às vezes lá do outro lado da rua, ele [padrasto] dizia: "Você não pode deixar porque hoje em dia as coisas tão muito violentas, muito perigoso e você não pode deixar ela tá saindo com amiga". Ele sempre colocava obstáculo pra ela não sair de dentro de casa com as amigas e depois do que aconteceu [revelação do abuso para a mãe] foi que a Joana veio começar a viver a adolescência. Ela não vivia e isso ajudou muito ela se levantar.

A reação materna diante da revelação dos abusos é considerada pelos estudiosos como um importante mediador capaz de neutralizar ou potencializar os sintomas na vítima (Santos \& Dell’ Aglio, 2009). Na entrevista de Cláudia, suas palavras relatam a fase da negação da mãe diante da revelação do abuso:

Ela teve até assim, em relação à dúvida se denunciava, se não denunciava, ela não queria tanto denunciar, porque em algum momento ela quase não acredita na Joana. Por que? Porque a Joana chamava ele [agressor] de tio, ela abraçava ele e ele[agressor] também abraçava ela. Ela [Maria] disse assim: “Cláudia como é que a Joana abraça, conversa com ele, fica ali numa família normal, todos nós somos uma família normal, de repente a Joana me solta essa"?

As palavras da mãe, ainda sob o impacto da revelação da filha, elucidam as percepções que a mesma tinha sobre o contexto familiar. Além disso, sugere que havia uma total confiança no agressor, realidade corroborada por muitos relatos de mães de vítimas de abusos intrafamiliar (Santos \& Dell'Aglio, 2008). Esse momento, vivido pela mãe como uma ameaça pode ser um mobilizador tanto para proteger a filha, bem como para proteger sua visão idealizada de família (Narvaz \& Koller, 2006), confirmando assim a reação materna como mediadora em casos de abuso sexual intrafamiliar (Santos et al., 2010).

A mãe também sofreu ameaças da filha mais velha (adulta) do agressor. A ameaça que a família sofre do agressor, direta ou indiretamente, é um evento que pode motivar a desistência da notificação do abuso (Santos et al.,2010). Portanto, deve ser considerado como outro mediador nas decisões da mãe, o qual é capaz de alterar a trajetória da família em direção a desfechos que desprotegerão a vítima. As palavras de Maria sobre as ameaças da filha mais velha do agressor:

"Maria, tu sabe que se tu tiver mentindo mais a tua filha, tu sabe o que é que vai sobrar pra ti, se fulano de tal, que era o 
irmão dela, que é ex-presidiário souber...". Então até essas ameaças eu ouvia no telefone, aí foi que determinei não atender mais o orelhão, porque tinha momento que eu ficava preocupada com ele [filho do agressor].

A participação tanto do pai biológico como do filho mais velho se deu por meio de conselhos à mãe no período da revelação do abuso sexual. Nesse sentido, Maria buscou a ajuda do pai-biológico de Joana e do filho mais velho, conforme os relatos do pai e do filho respectivamente:

Quando ela [Maria] me falou eu disse: "Olha, a decisão fica nas tuas mãos" (...)Assim eu vejo também pelo lado da humanidade, pois ele [agressor] é um velho, com problemas cardíacos (...) Então eu disse para ela [Maria]: "Você tem que denunciar. Expulse ele de casa e denuncie!".

Minha participação foi mais, digamos assim, em relação a conselhos, pois ele [agressor] representava uma ameaça para todos nós. Assim eu disse para ela [mãe] que aquilo não podia ficar do jeito que tava, ele tinha que sair".

Maria, diante da dúvida entre notificar ou não o agressor, ou por medo das ameaças sofridas, resolveu seguir os conselhos do paibiológico de Joana, primeiro colocá-lo para fora de casa, dando assim chance para o mesmo fugir e não ser preso, e depois denunciar, segundo a própria entrevistada. O afastamento do agressor de casa trouxe mudanças para a dinâmica de funcionamento da família, tal como relatado por Maria:

Mudou tudo, tudo, tudo! Você tem uma pessoa que lhe auxiliava, tipo assim, vai ali pegar uma ficha ali no posto, tu pega a ficha que daqui a pouco eu levo a menina pra consulta, a Melissa tinha problema de asma...

As palavras de Maria mostram que o marido se apresentava como uma pessoa que a auxiliava no cumprimento de várias tarefas, inclusive as relacionadas à maternidade, bem como era o provedor financeiro da casa:

Ele era aquele companheiro, pau para toda obra, a finança era toda com ele, o que eu tava ganhando era só um complemento, era um dinheiro que era meu que investia em alguma coisa (...) Porque o grosso era com ele, eu nunca me preocupei em relação a esse negócio de conta de água, de luz, 
gás. Eu fazia minha parte que era economizar e essa parte era todinha com ele.

Os relatos de Maria, portanto, sugerem uma dependência emocional e financeira da mesma para com o agressor. Tal realidade é frequente em casos de abuso sexual infantil intrafamiliar, visto que nesse contexto, na maioria das vezes, o perpetrador é também o provedor da casa (Santos, Costa, \& Granjeiro, 2009).

Nesse sentido, o afastamento do agressor da convivência com a família, uma possível consequência da revelação do abuso sexual da filha, se por um lado protegeu a vítima de novos abusos, por outro, desprotegeu a mãe, visto que neste caso havia dependência tanto emocional quanto financeira do agressor. Assim sendo, compreendese que o processo de revelação do abuso deve ser visto em sua ambiguidade, o que reitera a complexidade de tal fenômeno para o sistema familiar.

A dificuldade em enfrentar as consequências danosas que a revelação do abuso sexual intrafamiliar pode trazer para o sistema familiar foi ainda relatada por Cláudia, liderança da igreja, acerca das reações de Maria à violência perpetrada pelo companheiro à sua filha J oana:

Pela estrutura emocional da Maria eu acredito que não teria ido muito além, porque ela teve pensamentos terríveis de tirar até a própria vida. É tanto que no dia em que eu cheguei lá ela disse: "Ai amiga eu realmente preciso de um colo pra chorar". Eu pensei que o colo pra chorar era pra ficar conversando que nem nós duas aqui, mas não foi. Ela disse: "Deixa eu deitar no teu colo pelo amor de Deus". Ela deitou na minha perna e começou a chorar e disse: "Eu não sei o que fazer!".

\subsection{A rede de apoio no processo da revelação do abuso sexual}

A rede de apoio social e afetiva, em casos de abuso sexual intrafamiliar, é descrita como um elemento capaz de minimizar ou neutralizar o impacto da revelação dos abusos, ajudando no enfretamento da situação (Habigzang et al., 2006). Portanto, a atuação da rede de apoio para a família, no momento da revelação do abuso sexual, pode ser considerada um mediador importante.

No caso aqui analisado, verificou-se que a figura materna recorreu à ajuda da vizinha (Helena) durante o processo de revelação do abuso sexual, por exemplo, na ocasião em que buscou conselhos e informações de como deveria proceder com o agressor. Helena, por sua vez, por já ter sofrido uma ameaça de abuso na infância, ajudou Maria a entender a filha como vítima. Os depoimentos de Maria e 
Helena, respectivamente, comprovam a existência desse apoio recebido por Maria:

Deixo bem claro, foi muito importante aquelas palavras de Helena: "Você não fique como tá, você faça o que tem que ser feito[...] Maria corra enquanto é tempo, tira esse homem de dentro de casa."

Eu falei: “Maria, eu já passei por isso, eu sei o que é isso. Você saber que tem uma pessoa ali, você tem nojo, você tem recusa, você... nossa é horrível! Você não pode fazer isso com sua filha, você tem que acreditar nela, você tem que tirar esse homem de dentro de casa, não tem como a sua filha conviver com um homem desse."

Igualmente, ressalta-se o apoio ofertado à família pela liderança da igreja (Cláudia):

Tanto eu [Cláudia] e meu esposo, como o pastor e a esposa dele, disse que ela [Maria] tinha que fazer essa denúncia. Disse que ela tinha que fazer essa denúncia porque era uma coisa grave e poderia se estender para as duas outras filhas [Melissa e Marcela]. O problema poderia se estender. Aí foi quando a gente conversou com ela, convenceu ela de ir até lá na delegacia.

Os depoimentos de Cláudia e Maria sugerem que Cláudia, ao mesmo tempo em que encorajou Joana a revelar os abusos para a mãe, foi uma das pessoas que ajudou a mãe a perceber seu papel de proteção para com a filha, encorajando a mesma a notificar o agressor. Portanto, pode-se afirmar que Cláudia foi uma importante fonte de apoio emocional para a família. Ao mesmo tempo, Helena encorajou e aconselhou Maria a agir de forma protetiva para com a vítima, informando sobre os direitos da mãe, oferecendo segurança, suporte e apoio emocional no momento da revelação à amiga Maria. Nesses termos, a ajuda de Cláudia e Helena, representaram importantes mediadores do impacto da revelação do abuso sexual, num contexto de elevado estresse para o sistema familiar.

A família do estudo buscou e obteve apoio não somente de pessoas da comunidade (vizinha e lideranças da igreja, por exemplo), mas também das instituições que trabalham com famílias em situação de vulnerabilidades, como o Centro de Referência de Assistência Social (CRAS) e o Centro de Referência Especial de Assistência Social (CREAS). No tocante ao CRAS, destaca-se a inserção da família no Programa Bolsa Família, conforme explicitado no relato de Cláudia: 
"Aí ela [Maria] também conseguiu entrar no Bolsa Família, arrumar um emprego, levantou a cabeça e foi trabalhar, que até então ela não conseguia, só chorava, só chorava".

A Instituição CREAS foi um importante apoio para a família, pois segundo prontuário da vítima, tão logo foi notificado sobre os abusos, rapidamente providenciou apoio à vítima, sendo esta encaminhada para atendimento na referida instituição. Contudo, as dificuldades diárias encontradas no contexto destas instituições dificultaram um apoio continuado, prejudicando um vínculo já estabelecido entre a Psicóloga e Joana. Os relatos da psicóloga que atendeu a vítima, na época, confirmou tal realidade: “Eu atendi a Joana em dois tempos, porque eu trabalhei no CREAS duas vezes, eu fiquei um tempo e saí, depois voltei".

Embora o apoio proporcionado à vítima tenha sido de forma descontinuada, foi um importante mediador do impacto da revelação do abuso, constituindo-se assim como um espaço de proteção. Tal fato ficou evidenciado durante a entrevista quando a própria vítima reconheceu a importância da psicóloga, "Foi muito importante pra mim a psicóloga do CREAS, a Marisa, acho que ela me ouviu bastante".

\section{Considerações finais}

O presente estudo buscou descrever a percepção do grupo familiar sobre o processo de revelação de uma situação de abuso sexual intrafamiliar. Para tanto, desenhou-se uma pesquisa com delineamento de estudo de caso único de uma família, na qual a vítima (entrevistada aos 17 anos) foi abusada pelo padrasto dos 9 aos 14 anos, quando ocorreu a revelação/denúncia da violência e o consequente afastamento do agressor.

A análise dos dados permitiu a visualização da família em estudo e do seu envolvimento em uma complexa teia de relações, a qual era composta por várias redes de relações que se influenciaram dinâmica e recursivamente. Nesse sentido, ao estabelecer uma relação entre os participantes, o estudo descreveu a rede de relações que se formou no processo da revelação do abuso sexual: grupo familiar (irmão mais velho e pai-biológico); a rede informal (vizinha e liderança da igreja) e a rede de apoio Institucional (CRAS e CREAS). Conhecendo as relações na qual a família está inserida, percebeu-se seu nicho ecológico e os apoios que ali podem ser encontrados. A contribuição da rede de apoio informal mostrou-se com um papel decisivo, influenciando, sobremaneira, as ações da família; seja no sentido de realizar a denúncia, mas também de sustentar a decisão 
tomada e suas consequências, através do apoio emocional que recebiam.

Reitera-se a importância do fortalecimento das relações comunitárias em famílias que vivenciaram a violência sexual, visto que o contexto comunitário poderá ser um importante nicho ecológico capaz de favorecer o processo de revelação do abuso sexual. Ao mesmo tempo, reforça-se a importância de que essa rede informal seja reconhecida na sua importância, sobretudo nas estratégias de intervenção voltadas às vítimas de abuso sexual e suas famílias, as quais são desenvolvidas pela saúde, educação e segurança pública.

Em termos metodológicos, reforça-se nesse artigo a importância da utilização da estratégia da Inserção Ecológica, a qual possibilitou maior proximidade com a realidade vivenciada pela família ao longo dos três meses em que durou a coleta de dados. A utilização do tempo de vinculação com a instituição somada à vinculação estabelecida com os participantes do estudo foi essencial para o estabelecimento de uma relação de confiança entre pesquisadora e participantes do estudo, característica essencial ao manejo dos desafios éticos que o cotidiano de pesquisa sobre essa temática impõe.

Ainda em termos metodológicos, sublinha-se a opção pelo delineamento qualitativo, a inclusão de múltiplos participantes e a adoção de diferentes técnicas de coleta de dados. Entende-se que ambos os aspectos permitem a triangulação de informações, assim como uma abordagem mais sistêmica - complexa e relacional acerca do abuso sexual intrafamiliar e do processo de revelação. Finalmente, uma vez que os dados obtidos na presente pesquisa são retrospectivos, de uma família que vivenciou a revelação do abuso sexual três anos antes da realização do estudo, sugere-se que em estudos futuros, possam ser privilegiadas também aquelas famílias que estão vivenciando o processo de revelação do abuso sexual.

\section{Referências}

Afonso, T., Silva, S. S. da C., Pontes, F. A. R., \& Koller, S. H. (2015). O uso do diário de campo na Inserção Ecológica em uma família de uma Comunidade Ribeirinha Amazônica. Psicologia \& Sociedade, 27(1), 131-141.

Baía, P. A. D., Veloso, M. M. X., Magalhães, C. M. C., \& Dell'Aglio, D. D. (2013). Caracterização da Revelação do Abuso Sexual de Crianças e Adolescentes: Negação, retratação e Fatores Associados. Temas em Psicologia, 21(1), 193-202.

Bardin, L. (1995). Análise de conteúdo. Lisboa: Edições 70. 
Böing, A., Crepaldi, M. A., \& Moré, C. L. O. O. (2008). Pesquisas com Famílias: Aspectos teóricos - metodológicos. Paidéia, 18(40), 251-266.

Brito, R. C., \& Koller, S. H. (1999). Desenvolvimento humano e rede de apoio social e afetivo. In A. M. Carvalho et al. (Org.), O mundo social da criança: Natureza e cultura em ação (pp. 116129). São Paulo: Casa do Psicólogo.

Bronfenbrenner, U. (1996). A ecologia do desenvolvimento humano: experimentos naturais e planejados. Porto Alegre: Artes Médicas. (Originalmente publicado em 1979).

Bronfenbrenner, U. (2011). Bioecologia do desenvolvimento humano: tornando os seres humanos mais humanos. Porto Alegre: Artmed.

Cecconello, A. M., \& Koller, S. H. (2003). Inserção ecológica na comunidade: uma proposta metodológica para o estudo de famílias em situação de risco. Psicologia: Reflexão e Crítica, 16(3), 515-524.

Cerqueira-Santos, E., Rezende, N., \& Correia, P. (2010). Adolescentes vítimas de exploração sexual: Um estudo de caso múltiplos. Contextos Clínicos, 3(2), 113-123.

Coutinho, M. M. L. (2015). Resiliência familiar: processos vivenciados por uma família com vítima de abuso sexual (Dissertação de Mestrado). Programa de Pós-Graduação em Psicologia, Universidade de Fortaleza, Ceará, Brasil.

Dias, T. L., Leite, L. L. G. (2014). Rede de apoio social e afetivo e estratégias de enfrentamento na doença falciforme: um olhar sobre a pessoa e a família. Psicologia em Revista, 20(2), 353373.

Dobke, V. M., Santos, S. S., \& Dell'Aglio, D. D. (2010). Abuso sexual intrafamiliar: da notificação ao depoimento no contexto processual-penal. Temas em Psicologia, 18(1), 167-176.

Estatuto da Criança e do Adolescente (ECA). (1990). Lei № 8.069, de 13 de Julho de 1990. Recuperado de http://www.planalto.gov.br/ccivil_03/LEIS/L8069.htm

Habigzang, L. F., Azevedo, G. A., Koller, S. H., \& Machado, P. X. (2006). Fatores de Risco e de Proteção na rede de atendimento a Crianças e Adolescentes Vítimas de Violência Sexual. Psicologia: Reflexão e Crítica, 19(3), 379-386.

Habigzang, L. F., Koller. S. H., Azevedo, G. A., \& Machado, P. X. (2005). Abuso Sexual Infantil e Dinâmica Familiar: Aspectos Observados em Processos Jurídicos. Psicologia: Teoria e Pesquisa, 21(3), 341-348.

Habigzang, L. F., Ramos, M. S., \& Koller. S. H. (2011). A revelação do abuso Sexual: As medidas adotadas pela rede de apoio. Psicologia: Teoria e Pesquisa, 27(4), 467-473. 
Inoue, S. R. V. \& Ristum, M. (2010). Violência sexual contra a criança: estratégias de enfrentamento adotadas pela mãe. Interamerican J ournal of Psychology, 44(3), 560-570.

Lima, J. A. \& Alberto, M. F. P. (2010). As vivências maternas diante do abuso sexual intrafamiliar. Estudos de Psicologia, 15(2), 129-136.

Lima, J. S. \& Deslandes, S. F. (2011). A notificação compulsória do abuso sexual contra crianças e adolescentes: uma comparação entre os dispositivos americanos e brasileiros. Interface Comunicação, Saúde, Educação, 15(38), 819-832.

Lugão, K. V. M. S. F., Gonçalves G. E., Gomes, I. M., Silva, V. P., Jacobson, L. S.V., \& Cardoso, C. A. A. (2012). Abuso sexual crônico: Estudo de uma série de casos ocorridos na infância e na adolescência. DST- Jornal Brasileiro de Doenças Sexualmente Transmissíveis, 24(3), 179-182.

Mattos, I. A., \& Lima, I. M. S. O. (2012). Maternidade e o abuso sexual infantil intrafamiliar: Garantir um colo protetor. Revista Brasileira de Crescimento e Desenvolvimento Humano, 22(3), 373-377.

Morais, N. A., Koller, S. H., \& Raffaelli, M. (2012). Rede de apoio, eventos estressores e mau ajustamento na vida de crianças e adolescentes em situação de vulnerabilidade social. Universitas Psychologica, 11(3), 779-791.

Morais, N. A., Lima, R. F. F., \& Fernandes, J. (2014). Adolescência e contexto familiar. In L. F. Habigzang, E. Diniz \& S. H. Koller (Orgs.) Trabalhando com adolescentes: teoria e intervenção psicológica (pp. 101-117). Porto Alegre: Artmed.

Narvaz, M. G., \& Koller, S. H. (2006). A Concepção de Família de uma Mulher-Mãe de Vítimas de Incesto. Psicologia: Reflexão e Crítica, 19(3), 395-406.

Nascimento, D. B., Rosa, M. E. (2015). O uso do Mapa dos Cinco Campos no estudo da rede de apoio social e afetiva de crianças vítimas de abuso sexual. Contextos Clínicos, 8(2), 173-185.

Paludo, S. S., \& Koller, S. H. (2005). Resiliência na Rua: Um estudo de caso. Psicologia: Teoria e Pesquisa, 21(2), 187-195.

Penso, M. A., Costa, L. F., Almeida, T. M. C. de, \& Ribeiro, M. A. (2009). Abuso sexual intrafamiliar na perspectiva das relações conjugais e familiares. Aletheia, 30, 142-157.

Rosa, E. M., \& Lira, M. O. de S. C. (2012). Violência Intrafamiliar contra crianças e adolescentes: rede de apoio e superação. Revista Brasileira de Crescimento e Desenvolvimento Humano, 22(2), 246-252.

Santos, S. S. dos, Costa, F. L., \& Granjeiro, I. A. C. L. (2009). Intervenção no abuso sexual intrafamiliar: ingerência invasiva ou proteção devida? Psico, 40(4), 515-523. 
Santos, S. S., \& Dell'Aglio, D. D. (2008). Compreendendo as mães de crianças vítimas de abuso sexual: ciclos de violência. Estudos de Psicologia (Campinas), 25(4), 595-606.

Santos, S. S., \& Dell'Aglio, D. D. (2009). Revelação do abuso sexual infantil: reações maternas. Psicologia: Teoria e Pesquisa, 25(1), 85- 92.

Santos, S. S., \& Dell'Aglio, D. D. (2010). Quando o silêncio é rompido: o processo de revelação e notificação de abuso sexual infantil. Psicologia \& Sociedade, 22(2), 328-335.

Santos, S. S., \& Dell'Aglio, D. D. (2013). O processo de revelação do abuso sexual na percepção de mães. Psicologia: Teoria e Prática, 15(1), 50-64.

Santos, S. S., Pelisoli C., \& Dell'Aglio, D. D. (2012). Desvendando segredos: padrões e dinâmicas familiares no abuso sexual infantil. In L. F. Habigzang \& S. H. Koller (Orgs.), Violência contra crianças e adolescentes: teoria, pesquisa e prática ( $p$. 55-68). Porto Alegre: Artmed.

Schönbucher, V., Maier, T., Mohler-Kuo, M., Schnyder, U., \& Landolt, M. A. (2014). Adolescent Perspectives on Social Support Received in the Aftermath of Sexual Abuse: A Qualitative Study. Archives of Sexual Behavior, 43(3), 571-586. doi: 10.1007/s10508-013-0230-x.

Silva, D. G., Gava, L. L., \& Dell'Aglio, D. D. (2013). Sintomas e quadros psicopatológicos em supostas vítimas de abuso sexual: uma visão a partir da psicologia positiva. Aletheia, 44(2), 235244.

Siqueira, A. C., \& Dell'Aglio, D. D. (2010). Crianças e Adolescentes institucionalizados: Desempenho escolar, satisfação de vida e rede de apoio social. Psicologia: Teoria e Pesquisa, 26(3), 407415.

Vasconcelos, Q. A., Yunes, M. A. M., Garcia, N. M. (2009). Um estudo ecológico sobre as interações da família com o abrigo. Paidéia, 19(43), 221-229.

Walsh, F. (2005). Fortalecendo a Resiliência Familiar. São Paulo: Roca.

World Health Organization and International Society for prevention of Child Abuse Neglect (WHO \& ISPCAN). (2006). Preventing child maltreatment: a guide to taking action and generating evidence. Geneva: World Health Organization.

Yin, R. K. (2010). Estudo de Caso: planejamento e métodos (4a . ed.). Porto Alegre: Bookman. 


\section{Endereço para correspondência Márcia Moraes Lima Coutinho \\ Universidade de Fortaleza}

Av. José Morais de Almeida, 1100, casa 28, Coaçu, Eusébio - CE, Brasil

Endereço eletrônico: mmarciacoutinho@gmail.com

\section{Normanda Araujo de Morais}

Universidade de Fortaleza

Programa de Pós-Graduação em Psicologia

Av Washington Soares, 1321 bloco N sl 13, Edson Queiroz, CEP 60811-905, Fortaleza - CE, Brasil

Endereço eletrônico: normandaaraujo@gmail.com

Recebido em: 18/02/2016

Reformulado em: 18/07/2017

Aceito em: 18/07/2017

\section{Notas}

* Mestre em Psicologia pela Universidade de Fortaleza (UNIFOR); Terapeuta de família e Casais; Integrante do Laboratório de Estudos dos Sistemas Complexos: casais, família e comunidade (Lesplexos).

** Doutora em Psicologia pela Universidade Federal do Rio Grande do Sul; Professora Titular do Programa de Pós-graduação em Psicologia da Universidade de Fortaleza (UNIFOR); Bolsista Produtividade II do CNPq; Coordenadora do Lesplexos.

Agradecimento: A primeira autora agradece à Fundação Cearense de Apoio ao Desenvolvimento Científico e Tecnológico (FUNCAP) pela Bolsa de Mestrado recebida.

Este artigo de revista Estudos e Pesquisas em Psicologia é licenciado sob uma Licença Creative Commons Atribuição-Não Comercial 3.0 Não Adaptada. 